Further Section

Stereotact Funct Neurosurg 1989;52:266

Contents Vol. 52, 1989 


\section{Stereptactic Neurosurgery}

Official Journal of the World Society for Stereotactic and Functional Neurosurgery Official Journal of the American Society for Stereotactic and Functional Neurosurgery

Founded 1938 as 'Confinia Neurologica' by E.A. Spiegel Continued 1975-1988 as 'Applied Neurophysiology' Editor

Ph.L. Gildenberg, Houston, Tex.

Assistant Editor

Patricia O. Franklin, Houston, Tex. 
Editorial Board

M. Dimitrijevic, Houston, Tex. E. Eidelberg, San Antonio, Tex. R.G. Grossman, Houston, Tex.

E. Hitchcock, Birmingham

E.I. Kandel, Moscow

P.J. Kelly, Rochester, Minn. L. Laitinen, Umea D.M. Long, Baltimore, Md. R. Marino, Sao Paulo

F. Mundinger, Freiburg i.Br. 
H. Narabayashi, Tokyo

B.S. Nashold, Jr., Durham, N.C.

G. Ojemann, Seattle, Wash.

T.S. Roberts, Seattle

GS. Rossi, Rome

J. Siegfried, Zurich

A. Struppler, Munich

R.R. Tasker, Toronto

J.U. Toglia, Philadelphia, Pa.

J.M. Van Buren, Chapel HUI, N.C.

$m m m$ 


\section{Contents Vol. 52,1989}

No. 1 Intraoperative Impedance Monitoring during CT-Guided Stereotactic Biopsies Bullard, D.E.

Effects of Corpus Callosum Stimulation on the Morphology and Frequency of Epileptic Bursts in the Feline Topical Penicillin Generalized Model

Cukiert, A.; Baumel, S.W.; Andreolli, M.; Marino, R., Jr.

Stimulation of Locus Coeruleus in Man. Preliminary Trials for Spasticity and Epilepsy

Feinstein, B.; Gleason, C.A.; Libet, B.

Effect of Spinal Cord Stimulation on Motor Performances in Hemiplegics

Cioni, B.; Meglio, M.; Zamponi, A.....

Transcutaneous Electrical Nerve Stimulation and Spinal Cord Stimulation for Pain Relief

in Reflex Sympathetic Dystrophy

Robaina, F.J.; Rodriguez, J.L.; Vera, J.A. de; Martin, M.A

Analysis of Neuroelectric Implant Integrity

Harris, G.F.; Hemmy, D.C.; Coad, J.E.; Mothkur, S.R.; Weber, R.C

Announcements

No. 2-4 Proceedings of the Meeting on the Use of Microphysiological Recordings during Stereotactic Neurosurgery

Opening Remark

Narabayashi, $\mathrm{H}$.

Connectivity Patterns of Thalamic Nuclei Implicated in Dyskinesia

Carpenter, M.B

Recordings of Abnormal Activity in Patients with Deafferentation and Central Pain

Hirayama, T.; Dostrovsky, J.O.; Gorecki, J.; Tasker, R.R.; Lenz, F.A.

Evoked Potentials from the Human Thalamus: Correlation with Microstimulation and Single Unit Recording

Yamashiro, K.; Tasker, R.R.; Iwayama, K.; Mori, K,; Albe-Fessard, D.; Dostrovsky, J.O.; Chodakiewitz, J.W

Microrecording for the Study of Thalamic Organization, for Tumor Biopsy and Removal Ohye, C;

Shibazaki, T.; Hirai, T.; Matsumura, M.; Kawashima, Y.; Hirato, M. .. 136

Electrophysiological Recordings during Spinal Surgery

Uematsu, S.; Tolo, V

Electrophysiological Characterization of Human Subcortical Structures by Frequency

Spectrum Analysis of Neural Noise (Field Potential) Obtained during Stereotactic Sur gery. Preliminary Presentation of Frequency Power Spectrum of Various Subcortical Structures

Yoshida, M 
Functional Neuroanatomy of the Target Area for the Treatment of Pathological Tremor: an Electrophysiological Approach

Birk, P.; Struppler, A

Mapping of Semimicroelectrode Stimulation Response in and arround the Thalamus

Yoshida, $\mathrm{M}$

Mesothalamic Discharge Sites

Andy, O.J

Microphysiological Recordings at CT Gantry Site during Stereotactic Thalamotomy

Uematsu, S.; Delong, M.; Jankel, W.; McArthur, J.; Rosenbaum, A.E.; Nauta, H.; Nara-

bayashi, $\mathrm{H}$

Lateral Coordinates of Nucleus ventralis intermedius Target for Tremor Alleviation

Maeda, T

Striatal Symptoms

Narabayashi, $\mathrm{H}$

Stereoencephalotomy and Control of Skeletal Muscle Tone

Struppler, A

Thalamic Stimulation and Recording in Patients with Deafferentation and Central Pain

Gorecki, J.; Hirayama, T.; Dostrovsky, J.O.; Tasker, R.R.; Lenz, F.A

Electrical Stimulation Across the Midline and Between Basal Ganglion Nuclei

Heimburger, R.F.

New Trends in Computer Graphics and Computer Vision to Assist Functional Neurosurgery

Lipinski, H.G.; Struppler, A

A Method for MRI and CT Mapping of Diencephalic Somatotopography

Hardy^JT.L

Intraoperative CT-Guided Serial Microbiopsy of Brain Lesions and Concomitant Use of

CT Air and Angiographic Studies

Uematsu, S.; Erozan, Y.S.; Gupta, P.K.; Kumar, A.A.J.; McArthur, J.; Rosenbaum, A.E. 250

Announcements

Author Index

Subject Index 